\title{
Transgenerational Inheritance of Paternal Neurobehavioral Phenotypes: Stress, Addiction, Ageing and Metabolism
}

Ti-Fei Yuan; Ang Li; Xin Sun; Huan Ouyang; Carlos Campos; Nuno B. F. Rocha; Oscar AriasCarrión; Sérgio Machado; Gonglin Hou; Kwok Fai So

\begin{abstract}
Epigenetic modulation is found to get involved in multiple neurobehavioral processes. It is believed that different types of environmental stimuli could alter the epigenome of the whole brain or related neural circuits, subsequently contributing to the long-lasting neural plasticity of certain behavioral phenotypes. While the maternal influence on the health of offsprings has been long recognized, recent findings highlight an alternative way for neurobehavioral phenotypes to be passed on to the next generation, i.e., through the male germ line. In this review, we focus specifically on the transgenerational modulation induced by environmental stress, drugs of abuse, and other physical or mental changes (e.g., ageing, metabolism, fear) in fathers, and recapitulate the underlying mechanisms potentially mediating the alterations in epigenome or gene expression of offsprings. Together, these findings suggest that the inheritance of phenotypic traits through male germ-line epigenome may represent the unique manner of adaptation during evolution. Hence, more attention should be paid to the paternal health, given its equivalently important role in affecting neurobehaviors of descendants.
\end{abstract}

\section{Keywords}

Transgenerational inheritance; Sperm; Epigenetic modulation; Neurobehavior

\section{Introduction}

Epigenetics literally stands for "outside of genetics". In genetics, alterations in the sequence of genetic DNA result in gene expression and subsequent cellular phenotypes, whereas in epigenetics, the phenotypic trait variations can be caused by external or environmental factors that control gene expression at the transcriptional level, without affecting the DNA sequence per se $[1,2]$. Recent studies have suggested that epigenetic modulation participates in various types of neurobehavioral processes through DNA methylation/ demethylation [3, 4], histone acetylation/deacetylation [5], and transcriptional regulators (CREB, MeCP2, noncoding RNAs) [6] to alter synaptic plasticity/transmission, neuronal responses, and finally animal behaviors under both physiological and pathological conditions [7-9]. Epigenetic processes have a crucial role in determining parental imprints, management of gene expression, and regulation of germ cell development [10]. The potential regulation on germ line plasticity by the environment has been mainly based on the observation that external factors (e.g., stress, odors, high-fat diets) can induce epigenetic marks in the germ line [11-13]. Several epigenetic marks were found in sperm including noncoding RNAs, histone modifications, and DNA methylation [14]. These studies helped to understand how dynamic and plastic germs cells can be, although there is a need to further understand how and when these epigenetic marks can develop within the germ cells [10]. Traditionally, there are three types of pathways by which environmental 
factors can induce heritable changes in multicellular organisms with a germ line: direct induction, parallel induction, and somatic induction $[15,16]$. In direct induction (or gametic induction), challenging conditions affect the germ line directly even if parent organisms do not respond phenotypically. In parallel induction, the same cause independently induces epigenetic changes both in the soma and in the germ line. Thus, germ-line changes are directly induced without somatic mediation, and similar somatic phenotypes are displayed by the parents and its descendants. In contrast, somatic induction is characterized by soma-mediated germ-line changes. Alterations that first occur in the soma are transmitted to the germ line, subsequently inducing the parental phenotypes on the descendants. Small RNAs are able to travel between cells and may be the underlying mechanism to somatic induction [14]. Hormones have also been speculated as possible mediators of information transfer between the soma and the germ line, although the role of the two agents in this process remains poorly understood [14]. Recently, a fourth mechanism designating parallel induction with nonparallel effects has been explored. In this case, there is an induced effect on the soma of the parent which may cause changes in the germ line, with the resulting somatic adjustments of the descents that are different from the ones observed in the parents $[15,16]$.

With regard to the specific molecular mechanisms mediating the transfer of epigenetic information between two generations, DNA methylation has been the most popular candidate, although histone modifications and RNA have been also considered as valuable alternatives [17-19]. Prions and selfsustaining loops have also been suggested as possible epigenetic mechanisms, but there is no evidence supporting that they are transmitted between generations through sperm and egg [20]. However, there are studies describing that chromatin marks and RNAs can be transmitted between generations through the germ line, although it is unclear how this occurs $[15,16]$. One hypothesis is that the preservation of some partial chromatic marks or histone modification may allow the reconstruction of ancestral epigenetic patterns in the descendants [21]. In male vertebrates, the erasure of histone marks is not total, although there is broad replacement of histones by protamines during gametogenesis [22]. Cells in the germ line also contain small RNAs which are strong candidates to the inheritance process since they guide DNA and histone modification [20]. For example, piRNAs (Piwiinteracting RNAs) have a crucial role in detecting, silencing, or deleting unpaired DNA regions during meiosis [23]. Mammalian spermatocytes and oocytes are filled with large amounts of RNA of all classes, which suggests that they may be transmitted to the next generation and lead to transgenerational effects [18]. Next, we specifically discuss three common types of factors that have been implicated to enable the transgenerational inheritance of paternal neurobehavioral phenotypes, including stress, addictive drugs, and physical or mental changes in fathers (Fig. 1). We also conclude the evidence supporting the involvement of DNA methylation, histone acetylation, and miRNAs (microRNAs) in this biological process.

\section{Stress}

\section{Stress-Induced Epigenetic Modulation in the Brain}

\section{DNA Methylation}

Acute or chronic stress experiences can lead to epigenetically modulated changes of gene expression in stress-responsive brain regions [24-26]. For instance, the early-life stress experience raised the expression of arginine vasopressin (AVP) in the paraventricular nucleus 
(PVN) of the hypothalamus due to the hypo-methylation of the DNA binding sites for Methyl CpG binding protein 2 (MeCP2), which mediates the activity-dependent transcription [27]. Chronic social stress demethylated the corticotrophin releasing factor (CRF) Crf gene selectively in the stress-responsive animals rather than their resilient counterparts [28]. Moreover, the expression of DNA methyltransferases 3a (Dnmt3a) was modulated by chronic stress or drug exposure, which then contributed to the changes of spine plasticity in the nucleus accumbens (NAC) and behaviors in the animals [29].

\section{Histone Acetylation}

Besides DNA methylation, histone modification is well noted in stress-induced brain changes. Histone deacetylase 6 (HDAC6) has been revealed to be crucial for acute stresselicited potentiation of glutamatergic transmission in the prefrontal cortex [30]. Both siRNA knockdown and pharmacological inhibition of HDAC6 blocked the synaptic changes induced by force-swimming stress in vivo, or by corticosterone treatment in vitro in rats. Likewise, HDAC5 also plays an important role in the pathophysiology and treatment of depression. Chronic administration of imipramine, a tricyclic antidepressant that hyperacetylates histone to promote the transcription of certain splice variant mRNAs of brain-derived neurotrophic factor (BDNF), resulted in a decrease in Hdac5, whereas over-expressing HDAC5 in the hippocampus diminished the antidepressive capacity of imipramine [31]. Chronic social defeat stress in mice enhanced $\mathrm{H} 3$ acetylation while lowered HDAC2 levels in the NAc, in contrast to the infusion of HDAC inhibitors into the NAc that was demonstrated to exert antidepressant-like effects [32]. In another study, it was found that the epigenetic modulation of RAS-related C3 botulinum toxin substrate 1 (Rac1) expression in the NAc orchestrated the synaptic remodeling induced by chronic stress in mice. Moreover, the prolonged reduction in Rac1 expression could be rescued with HDAC inhibitors [7].

\section{miRNAs}

Last but not least, recent findings have highlighted the indispensability of microRNAs for the therapeutic effects of antidepressants [33]. Specifically, miR135 was reported to be critical to the excitability of serotonergic neurons, mediating the susceptibility and heterogeneity to chronic stress. In a very recent study, Rodgers and colleagues demonstrated that zygotic microinjection of nine microRNAs, whose expression levels have been confirmed to be significantly raised in the sperm of male mice exposed to chronic stress [34], could degrade several important maternal mRNA targets in early zygotes. As a consequence, adult offsprings from these manipulated zygotes exhibited the blunted hypothalamic-pituitary-adrenal stress axis response and altered PVN transcriptome, which together recapitulated the effects of paternal stress [35]. Taken together, these findings raised the possibility to therapeutically fight against stress with agents enabling the epigenetic regulation, particularly those capable of affecting the paternal germ line epigenome.

\section{The Inheritance of Stress-Related Neurobehavioral Changes}

It has been long known that stress could impair sex-related performances, decrease sperm count and quality, and harm testicular cells, lasting from months to years [36, 37]. Until 
recently, it was unveiled that stress-induced behavioral adaptations in male individuals could be transmitted to their offsprings [38,39] potentially through the sperm epigenome [34]. For example, sperm small-noncoding RNAs (sncRNAs) contain miRNA, piRNA, and rbRNA (ribosomal RNA). In an early-life stress mouse (FO generation) model of unpredictable maternal separation combined with unpredictable maternal stress (MSUS), the expression levels of different miRNAs were altered in serum, stress-relevant brain regions, as well as sperm RNAs $[40,41]$, which were correlated to the presence of a series of stress-relevant behaviors. Interestingly, such changes were detected in the brain structures but not sperms of the F1 generation animals, even though both F1 and F2 generation animals exhibited similar behavioral changes as FO MSUS animals [40]. Of note, injecting the isolated sperm RNAs from FO animals into fertilized oocytes was sufficient to produce the behavioral phenotype observed in F1 animals [40], suggesting a new way to modulate the parental effect traits or even to treat certain inherited diseases, in a "father-to-son" manner. It will be as well important to understand how stress could impact the sncRNAs in the sperm so as to develop strategies to prevent such changes in people with high-stress professions. In another study from the same group, the behavioral changes in F1 generation animals were attributed to those of different plasticity-related genes in the brain, together with the impaired hippocampal long-term potentiation (LTP) while enhanced long-term depression (LTD) [42]. Moreover, the altered synaptic plasticity was correlated to the decreased methylation level of the promoter region of protein kinase $\mathrm{C}$ gamma (PKC-gamma) Prkcc in F1 generation, a neuron-specific form of PKC which is involved in synaptic plasticity [42]. Surprisingly, such methylation decrease was not found in $\mathrm{FO}$ generation animals even in the presence of altered synaptic plasticity and behaviors; therefore, it is highly possible that the F0 sperm miRNA alterations were transferred to the F1 brain structures and coded as DNA methylation changes for the longer-term stability.

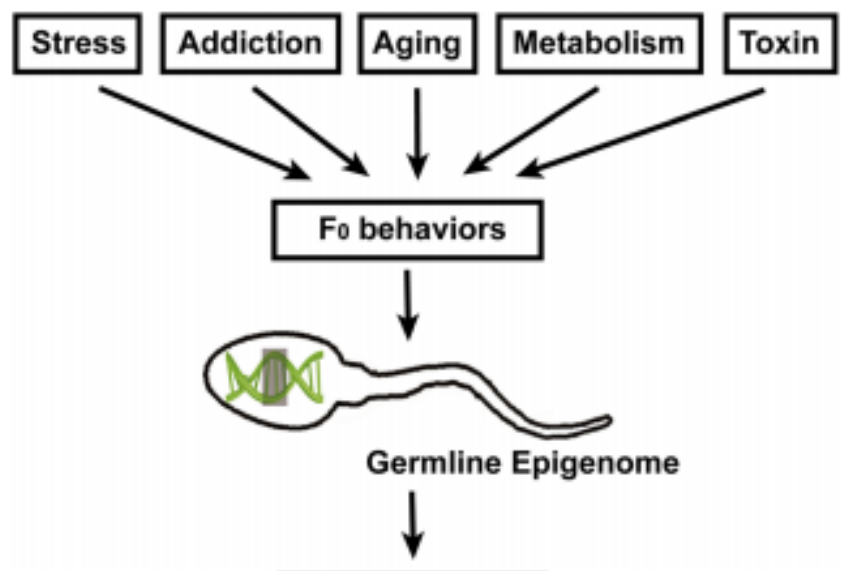

F1 behaviors

Fig. 1 Transgenerational inherence of neurobehavioral phenotypes through germ-line epigenome. The environment experiences such as stress, addictive drugs, and chemical exposure lead to behavioral adaptations in parents (F0), as well as the offspring (F1) through germline epigenome regulation

\section{Reward and Drug Addiction}

\section{Epigenetic Mechanisms of Drug Addiction}


Addiction represents the drug-induced long-lasting changes in the brain that drive compulsory behaviors of drug seeking. In the past decade, the epigenetic mechanism has been considered as one important player in maintaining these lasting effects, especially through the regulation of synaptic plasticity [43-45]. There were lines of evidence showing that acute or chronic exposure to drugs of abuse resulted in epigenetic changes in reward-related brain regions (e.g., midbrain dopamine neuron and NAc), whereas blockade of these changes could delay or decrease the formation of addiction-related behaviors.

\section{DNA Methylation}

For instance, the transcription levels of DNMT3a in the NAc were firstly (after $4 \mathrm{~h}$ ) upregulated and then downregulated (after $24 \mathrm{~h}$ ) in both acute and chronic exposures to cocaine $[29,46]$. The decreased expression or blockade of DNMT3a function was found to increase the behavioral response to cocaine exposure, and vice versa for the overexpression experiment, accompanying changes in spine density and druginduced synaptic plasticity [29]. In addition, chronic cocaine exposure decreased Teneleven translocation methylcytosine dioxygenase 1 (TET1) expression in the NAc, in turn, knocking down TET1 enhanced the addictive behaviors [44]. The dysregulation of methylation was accompanied by altered MeCP2 expression: MeCP2 knockdown promoted the drug-reward behaviors [47]. Future studies are yet required to identify the genomewide methylation changes in animal models of drug addiction and in human postmortem brain samples.

\section{Histone Acetylation}

There were rigorous studies linking histone modification to certain phase(s) of drug addiction. It was found that cocaine (or other drugs of abuse) exposure resulted in increased levels of acetylated $\mathrm{H} 3$ (or $\mathrm{H} 4$ ) in the $\mathrm{NAc}$, and the manipulation of which could contribute to altered behavioral responses as well [48-54]. Additionally, the NAc-targeted overexpression of HDAC4/5 attenuated the cocaine-relevant behavioral response, whereas the HDAC5 deletion promoted behavioral sensitivity to cocaine $[48,52,55]$. On the other hand, the NAc-selective deletion of HDAC1 mitigated the cocaine response [56], while downregulating HDAC3 facilitated the extinction of cocaine CPP [54]. Chronic cocaine exposure also increased the expression of SIRT1/2 [57]; the molecular targets of these two HDACs are to be investigated. These results collectively pointed out the complexity of histone acetylation regulation during the formation of addictive behaviors and that each step might be controlled by different signaling molecules. The altered histone acetylation was linked to the drug exposure-induced expression of immediate early genes and drug-evoked synaptic plasticity. For instance, $\mathrm{H} 4$ acetylation was found to occur at the c-Fos promoter region upon acute drug exposure [58], possibly through G9a $[51,59]$. Likewise, H3 acetylation was increased at the BDNF promoter region after chronic cocaine administration [48]. Increases in $\mathrm{H} 3$ acetylation were also reported at promoter sites for Cdk5 and CaMKII $[48,60]$, which have been proven important for the drug-evoked synaptic plasticity well recognized in the NAc [61].

\section{miRNAs}


Cocaine exposure resulted in increased expressions of miR181a and miR212 [62-64] and decreased expression of miR124 and let-7d in the striatum [65]. This has been linked to altered CREB activation [63] or glutamate receptor trafficking in the neuron [66].

\section{Transgenerational Susceptibility to Drug Abuse}

Parental experience of drug addiction is found to affect the offspring susceptibility to the same drug of abuse. In a rat model of cocaine self-administration (FO), the offspring males (F1) rather than females developed a cocaine-resistant phenotype, including delayed acquisition and reduced maintenance of the self-administration [67]. The drug-resistant behavior was accompanied by the increased association of histone $\mathrm{H} 3$ to the BDNF promoter region, and the upregulated BDNF mRNA transcription as well as protein expression in the medial prefrontal cortex of male individuals of the F1 generation. Interestingly, this was attributed to the increased BDNF promoter acetylation in the sperm from the F0 generation (cocaine-exposed animals) [67]. It is yet unknown how sperm BDNF DNA acetylation is selectively modulated by cocaine administration and whether this will be inherited by the F2 generation. In another study, it was reported that maternal exposure to cocaine prior to pregnancy led to altered behavioral responses to cocaine, as well as upregulation of D1 receptor expression selectively in male offsprings [68], suggesting that there might be different effects dependent on the sex of the parent of origin. Other lines of studies demonstrated that parental use of alcohol prior to mating could give birth to offsprings with altered brain structures and functions $[69,70]$. In a recent study with two-bottle choice of free alcohol intake, it was found that alcohol consumption was selectively decreased in male offsprings from parents with previous alcohol abuse experience [71]. On the other hand, these animals exhibited increased anxiety and locomotion induced by alcohol. Moreover, these changes were accompanied by BDNF Exon IXa expression in midbrain dopamine neurons, due to the decreased promoter methylation [71]. Taken together, the transgenerational inheritance of the drug susceptibility is to be investigated in details with different animal models, in order to understand the mechanisms of persistence. In addition, many studies have reported the effects of drugs on in utero development of the brain [72-75], with postnatal behavior changes. It will be as well interesting to know if addictive drugs modulate such behaviors through epigenetic mechanisms. In fact, there have already been pilot data showing the altered MeCP2 binding to the BDNF promoter in mice with in utero cocaine exposure [76].

\section{Others}

\section{Ageing}

Advanced parental age has been associated with increased risks of various neurodevelopmental disorders and psychiatric diseases [77, 78], through, for example, de novo mutation. In one study, it was found that ageing was coincidental with numerous alterations of DNA methylation (F0 generation), which were then transmitted to the offsprings (F1), contributing to a variety of behavioral changes, such as the open-field exploratory activities and the pre-pulse inhibition [79]. In future, it will be interesting to dissect the most relevant genes and neural circuits that are affected by these methylation changes, for the potential rescue of the functional abnormalities. 


\section{Olfactory Fear Conditioning}

Olfactory sensation and fear conditioning are critical for escaping from the predators and the species survival. The ability of fast learning and extinction to adapt the new environment is therefore with evolutionary importance. It was found that odor fear conditioning in F0 male animals caused the same odorinduced startles in both F1 and F2 offspring generations [12]. Interestingly, the odor acetophenone induced fear conditioning in FO male animals resulted in the increased innervation area (glomerulus area) of the relevant odorant receptor (Olfr151)expressing olfactory sensory neurons, in both F1 and F2 generations. Such an effect was due to the decreased Olfr151 gene methylation in F0 and F1 sperm DNA [12]. In this study, the authors did not detect any histone-relevant modifications on the same locus. It is possible that different epigenetic mechanisms are differentially recruited for modulation of distinct neural pathways; yet the "sorting" mechanism is completely unknown.

\section{Endocrine Function and Metabolism}

It was reported that administration of antiandrogenic fungicide vinclozolin in parents could result in decreased spermatogenic capacity in male offsprings [80, 81], altered sexual selection behaviors [82], and different behavioral responses to stress in following generations [83, 84]. The mechanisms may involve the altered DNA methylation selectively in the male germ line [85-87], especially the sperm epigenome [88]; yet in certain behavioral aspects, the female offsprings could be more vulnerable as well [89], showing the sexually dimorphic effects. There was evidence suggesting that other endocrinedisrupting agents (e.g., diethylstilbesterol, bisphenol $A$, and polychlorinated biphenyls) could exhibit transgenerational neuroendocrine modulation as well [90]. Interestingly, parental life experiences that affect the body metabolism could also modulate the neuroendocrine function in offspring generations. For instance, food deprivation in F0 generation mice led to decreased serum glucose levels in both male and female offsprings (F1) [91], whereas the high-fat diet in male rats (F0) selectively resulted in pancreatic betacell dysfunction in female offsprings [13], showing the "father-todaughter" inheritance through the hypo-methylation of different pancreas-specific genes (e.g., II13ra2). This implied that the parental lifestyles could significantly impact the metabolic function of offspring kids, and even contribute to certain types of diseases (e.g., diabetes) [92, 93]. Indeed, a largescale investigation in human subjects showed that fathers (even grandparents) with pre-marriage malnutrition or early smoking experiences influenced the risks in their offsprings to cardiovascular disease or diabetes $[94,95]$. The other study examined the offspring generation (F1) of male animals (F0) fed with the low-protein diet from weaning until sexual maturity. The F1 generation exhibited elevated expressions of multiple genes related to lipid and cholesterol metabolism, which might result from the increased methylation (therefore decreased expression) of the key lipid regulator gene-Ppara in F1 F1 offsprings, although the involvement of other epigenetic information carriers like RNA and chromatin could not be excluded [96]. Interestingly, the Ppara expression was also affected by the maternal diet-high-fat maternal diet led to increased Ppara expression at birth and decreased expression at weaning [97]. How the different body metabolism states could selectively affect the epigenome in sperm or ova is yet to be studied. In line with the abovementioned results, malnutrition in F0 pregnancy led to the in utero undernourishment of F1 animals, subsequently altering the sperm DNA methylome of F1 adult males. Interestingly, although persistence of altered methylation was not observed in brain or liver tissues of lategestation (E16.5) F2 offsprings, they also displayed metabolic phenotypes, thereby suggesting a potential 
involvement of changes in methylation during the early developmental stage [98]. Collectively, environmental stimuli can impact the sperm methylome even before maturation of the individual; this may be due to the epigenetic changes in spermatogonium cells. Accordingly, the spermatogonium acts as a candidate target to prevent such transgenerational inheritance of certain diseased phenotypes.

\section{Epigenetic Modulation in Different Developmental Phases}

Taking into account the previous findings, it is clear that epigenetic processes produce a wide range of developmental variability, which can be induced by environmental factors and then transmitted to the following generations. However, for a transgenerational epigenetic inheritance via the gametes to occur, an epigenetic mark must be present in the germ cell and endure epigenetic reprogramming [17-19]. Hence, epigenetic marks have to be reprogrammed and reestablished in the absence of reexposure to the environmental stimuli. In sexually reproducing organisms, epigenetic variations have to survive the complex process of meiosis and be transmitted to the next generation; in multicellular organisms, they also have to survive early embryogenesis and gametogenesis, two developmental stages that involve significant restructuring of both cells and chromatin $[20,99,100]$. The first phase occurs soon after fertilization, where the paternal genome undergoes a wave of genome-wide DNA demethylation [99]. However, despite the severe reprogramming process, some epigenetic modifications escape this remodeling and allow for some information to be maintained until adulthood [101, 102]. The second and last period of major epigenetic reprogramming occurs during the developing of the male and female germ line, more specifically, in the post-migratory primordial germ cells (PGCs) [103]. This phase is a major barrier to transgenerational epigenetic inheritance, during which histone variants and their modifications, as well as small RNAs and DNA methylation, are all reset in order to give rise to functional gametes $[104,105]$. After this phase, the epigenome is at its most "naive" state and prepared for the acquisition of new epigenetic information and genomic imprints that will be transmitted to the next generation through mature gametes [99]. The complex processes previously described have led researchers to postulate that transgenerational epigenetic inheritance can be displayed by several patterns, where epigenetic information can be more or less closely reconstructed across generations [15]. The most commonly addressed possibility is the epigenetic recall, characterized by a partial reconstruction of epigenetic material. There is a partial inheritance of the epigenetic pattern that can be induced on the parent, without modified morphology in progeny. However, for the fullepigenetic pattern to be utterly reestablished, the progeny will need a reduced intensity of the environment inducer [106]. Other possibilities relate to reactive but dissimilar epigenetic effects, where the faithful inheritance of the epigenetic marks followed by an exposure of the progeny to different environments provides an entry point for new phenotypes [107]. There is also the possibility of directional changes across generations, which can be accumulative (inducing conditions persist leading to more extreme phenotypes) or lingering-fading (noninducing conditions for the offspring generations reduce the epigenetic marks and respective phenotypes) [108]. The preceding options represent only a small fraction of the possibilities, as transgenerational epigenetic inheritance involves rather complex mechanisms.

\section{Summary}


The transgenerational inheritance of epigenetic traits, together with the neurobehavioral adaptions to previous environmental stimuli, serves as an important mechanism during evolution. The epigenome lasts for only several generations, and the rapid removal of such "memory" allows further "writing" of new environmental conditions. The epigenome examinations also permit the prediction and potential therapy against certain birth defects resulted from environmental toxin/stress.

\section{References}

1. Bale TL (2015) Epigenetic and transgenerational reprogramming of brain development. Nat Rev Neurosci 16(6):332-344. doi:10. 1038/nrn3818

2. Klengel T, Binder EB (2015) Epigenetics of stress-related psychiatric disorders and gene $x$ environment interactions. Neuron 86(6): 1343-1357. doi:10.1016/j.neuron.2015.05.036

3. Day JJ, Childs D, Guzman-Karlsson MC, Kibe M, Moulden J, Song E, Tahir A, Sweatt JD (2013) DNA methylation regulates associative reward learning. Nat Neurosci 16(10):1445-1452. doi: 10.1038/nn.3504

4. Ma DK, Jang MH, Guo JU, Kitabatake Y, Chang ML, PowAnpongkul N, Flavell RA, Lu B et al (2009) Neuronal activityinduced Gadd45b promotes epigenetic DNA demethylation and adult neurogenesis. Science 323(5917):1074-1077. doi:10.1126/ science.1166859

5. Guan JS, Haggarty SJ, Giacometti E, Dannenberg JH, Joseph N, Gao J, Nieland TJ, Zhou Y et al (2009) HDAC2 negatively regulates memory formation and synaptic plasticity. Nature 459(7243): 55-60. doi:10.1038/nature07925

6. Monteggia LM, Kavalali ET (2009) Rett syndrome and the impact of MeCP2 associated transcriptional mechanisms on neurotransmission. Biol Psychiatry 65(3):204-210. doi:10.1016/j.biopsych. 2008.10.036

7. Golden SA, Christoffel DJ, Heshmati M, Hodes GE, Magida J, Davis K, Cahill ME, Dias C et al (2013) Epigenetic regulation of RAC1 induces synaptic remodeling in stress disorders and depression. Nat Med 19(3):337-344. doi:10.1038/nm.3090

8. Marques SC, Oliveira CR, Pereira CM, Outeiro TF (2011) Epigenetics in neurodegeneration: a new layer of complexity. Prog Neuropsychopharmacol Biol Psychiatry 35(2):348-355. doi:10.1016/j.pnpbp.2010.08.008

9. Kwok JB (2010) Role of epigenetics in Alzheimer's and Parkinson's disease. Epigenomics 2(5):671-682. doi:10.2217/ epi.10.43

10. 10. Bale TL (2014) Lifetime stress experience: transgenerational epigenetics and germ cell programming. Dialogues Clin Neurosci 16(3):297-305

11. Skinner MK (2014) Environmental stress and epigenetic transgenerational inheritance. BMC Med 12(1):153. doi:10. 1186/s12916-014-0153-y

12. Dias BG, Ressler KJ (2014) Parental olfactory experience influences behavior and neural structure in subsequent generations. Nat Neurosci 17(1):89-96. doi:10.1038/nn.3594

13. Ng SF, Lin RC, Laybutt DR, Barres R, Owens JA, Morris MJ (2010) Chronic high-fat diet in fathers programs beta-cell dysfunction in female rat offspring. Nature 467(7318):963966. doi:10. 1038/nature09491

14. Sharma A (2013) Transgenerational epigenetic inheritance: focus on soma to germline information transfer. Prog Biophys Mol Biol 113(3):439-446.

doi:10.1016/j.pbiomolbio.2012.12.003 
15. Jablonka E, Raz G (2009) Transgenerational epigenetic inheritance: prevalence, mechanisms, and implications for the study of heredity and evolution. Q Rev Biol 84(2):131-176

16. Jablonka E (2013) Epigenetic inheritance and plasticity: the responsive germline. Prog Biophys Mol Biol 111(2-3):99-107. doi:10.1016/j.pbiomolbio.2012.08.014

17. Casas E, Vavouri T (2014) Sperm epigenomics: challenges and opportunities. Front Genet 5:330. doi:10.3389/fgene.2014.00330

18. Daxinger $L$, Whitelaw $E$ (2012) Understanding transgenerational epigenetic inheritance via the gametes in mammals. Nat Rev Genet 13(3):153-162. doi:10.1038/nrg3188

19. Szyf M (2015) Nongenetic inheritance and transgenerational epigenetics. Trends Mol Med 21(2):134-144. doi:10.1016/j.molmed. 2014.12.004

20. 20. Heard E, Martienssen RA (2014) Transgenerational epigenetic inheritance: myths and mechanisms. Cell 157(1):95-109. doi:10. 1016/j.cell.2014.02.045

21. Margueron R, Reinberg D (2010) Chromatin structure and the inheritance of epigenetic information. Nat Rev Genet 11(4):285-296. doi:10.1038/nrg2752

22. van der Heijden GW, Derijck AA, Ramos L, Giele M, van der Vlag J, de Boer P (2006) Transmission of modified nucleosomes from the mouse male germline to the zygote and subsequent remodeling of paternal chromatin. Dev Biol 298(2):458-469. doi: 10.1016/j.ydbio.2006.06.051

23. Kim VN (2006) Small RNAs just got bigger: Piwiinteracting RNAs (piRNAs) in mammalian testes. Genes Dev 20(15):1993- 1997

24. Yuan TF, Hou G (2015) The effects of stress on glutamatergic transmission in the brain. Mol Neurobiol 51(3):1139-1143. doi: 10.1007/s12035-014-8783-9

25. Nestler EJ (2014) Epigenetic mechanisms of depression. JAMA Psychiatry 71(4):454456. doi:10.1001/jamapsychiatry.2013. 4291

26. Vialou V, Feng J, Robison AJ, Nestler EJ (2013) Epigenetic mechanisms of depression and antidepressant action. Annu Rev Pharmacol Toxicol 53:59-87. doi:10.1146/annurev-pharmtox-010611-134540

27. Murgatroyd C, Patchev AV, Wu Y, Micale V, Bockmuhl Y, Fischer D, Holsboer F, Wotjak CTet al (2009) Dynamic DNA methylation programs persistent adverse effects of earlylife stress. Nat Neurosci 12(12):1559-1566. doi:10.1038/nn.2436

28. Elliott E, Ezra-Nevo G, Regev L, Neufeld-Cohen A, Chen A (2010) Resilience to social stress coincides with functional DNA methylation of the Crf gene in adult mice. Nat Neurosci 13(11): 1351-1353. doi:10.1038/nn.2642

29. LaPlant Q, Vialou V, Covington HE 3rd, Dumitriu D, Feng J, Warren BL, Maze I, Dietz DM et al (2010) Dnmt3a regulates emotional behavior and spine plasticity in the nucleus accumbens. Nat Neurosci 13(9):1137-1143. doi:10.1038/nn.2619

30. Lee JB, Wei J, Liu W, Cheng J, Feng J, Yan Z (2012) Histone deacetylase 6 gates the synaptic action of acute stress in prefrontal cortex. J Physiol 590(Pt 7):1535-1546. doi:10.1113/jphysiol. 2011.224907

31. Tsankova NM, Berton O, Renthal W, Kumar A, Neve RL, Nestler EJ (2006) Sustained hippocampal chromatin regulation in a mouse model of depression and antidepressant action. Nat Neurosci 9(4): 519-525. doi:10.1038/nn1659

32. Covington HE 3rd, Maze I, LaPlant QC, Vialou VF, Ohnishi YN, Berton O, Fass DM, Renthal W et al (2009) Antidepressant actions of histone deacetylase inhibitors. J Neurosci 29(37):11451-11460. doi:10.1523/JNEUROSCI.1758-09.2009

33. Issler O, Haramati S, Paul ED, Maeno H, Navon I, Zwang R, Gil S, Mayberg HS et al (2014) MicroRNA 135 is essential for chronic stress resiliency, antidepressant efficacy, 
and intact serotonergic activity. Neuron 83(2):344-360. doi:10.1016/j.neuron.2014.05. 042

34. Rodgers AB, Morgan CP, Bronson SL, Revello S, Bale TL (2013) Paternal stress exposure alters sperm microRNA content and reprograms offspring HPA stress axis regulation. J Neurosci 33(21): 9003-9012. doi:10.1523/JNEUROSCI.0914-13.2013

35. Rodge rs AB, Mo rgan CP, Leu NA, Bale TL (2015) Transgenerational epigenetic programming via sperm microRNA recapitulates effects of paternal stress. Proc Natl Acad Sci U S A. doi:10.1073/pnas.1508347112

36. Hou G, Xiong W, Wang M, Chen X, Yuan TF (2014) Chronic stress influences sexual motivation and causes damage to testicular cells in male rats. J Sex Med 11(3): 653663. doi:10.1111/jsm.12416

37. Gollenberg AL, Liu F, Brazil C, Drobnis EZ, Guzick D, Overstreet JW, Redmon JB, Sparks A et al (2010) Semen quality in fertile men in relation to psychosocial stress. Fertil Steril 93(4):1104-1111. doi:10.1016/j.fertnstert.2008.12.018

38. Dietz DM, Laplant Q, Watts EL, Hodes GE, Russo SJ, Feng J, Oosting RS, Vialou V et al (2011) Paternal transmission of stressinduced pathologies. Biol Psychiatry 70(5):408414. doi:10.1016/ j.biopsych.2011.05.005

39. Franklin TB, Russig H, Weiss IC, Graff J, Linder N, Michalon A, Vizi S, Mansuy IM (2010) Epigenetic transmission of the impact of early stress across generations. Biol Psychiatry 68(5):408-415. doi:10.1016/j.biopsych.2010.05.036

40. Gapp K, Jawaid A, Sarkies P, Bohacek J, Pelczar P, Prados J, Farinelli L, Miska E et al (2014) Implication of sperm RNAs in transgenerational inheritance of the effects of early trauma in mice. Nat Neurosci 17(5):667-669. doi:10.1038/nn.3695

41. Sharma U, Rando OJ (2014) Father-son chats: inheriting stress through sperm RNA. Cell Metab 19(6):894-895. doi:10.1016/j. cmet.2014.05.015

42. Bohacek J, Farinelli M, Mirante O, Steiner G, Gapp K, Coiret G, Ebeling M, DuranPacheco $\mathrm{G}$ et al (2015) Pathological brain plasticity and cognition in the offspring of males subjected to postnatal traumatic stress. Mol Psychiatry 20(5):621-631. doi:10.1038/mp. 2014.80

43. Robison AJ, Nestler EJ (2011) Transcriptional and epigenetic mechanisms of addiction. Nat Rev Neurosci 12(11):623-637. doi:10.1038/nrn3111

44. Nestler EJ (2014) Epigenetic mechanisms of drug addiction. Neuropharmacology $76 \mathrm{Pt}$ B:259-268. doi:10.1016/j. neuropharm.2013.04.004

45. Feng J, Nestler EJ (2013) Epigenetic mechanisms of drug addiction. Curr Opin Neurobiol 23(4):521-528. doi:10.1016/j.conb. 2013.01.001

46. Anier K, Malinovskaja K, Aonurm-Helm A, Zharkovsky A, Kalda A (2010) DNA methylation regulates cocaine-induced behavioral sensitization in mice. Neuropsychopharmacology 35(12): 2450-2461. doi:10.1038/npp.2010.128

47. Deng JV, Rodriguiz RM, Hutchinson AN, Kim IH, Wetsel WC, West AE (2010) MeCP2 in the nucleus accumbens contributes to neural and behavioral responses to psychostimulants. Nat Neurosci 13(9):1128-1136. doi:10.1038/nn.2614

48. Kumar A, Choi KH, Renthal W, Tsankova NM, Theobald DE, Truong HT, Russo SJ, Laplant $Q$ et al (2005) Chromatin remodeling is a key mechanism underlying cocaineinduced plasticity in striatum. Neuron 48(2):303-314. doi:10.1016/j.neuron.2005.09. 023

49. Shen HY, Kalda A, Yu L, Ferrara J, Zhu J, Chen JF (2008) Additive effects of histone deacetylase inhibitors and amphetamine on histone $\mathrm{H} 4$ acetylation, cAMP responsive element binding protein phosphorylation and DeltaFosB expression in the striatum 
and locomotor sensitization in mice. Neuroscience 157(3): 644-655.

doi:10.1016/j.neuroscience.2008.09.019

50. Schroeder FA, Penta KL, Matevossian A, Jones SR, Konradi C, Tapper AR, Akbarian S (2008) Drug-induced activation of dopamine $D(1)$ receptor signaling and inhibition of class $\mathrm{I} / \mathrm{II}$ histone deacetylase induce chromatin remodeling in reward circuitry and modulate cocaine-related behaviors. Neuropsychopharmacology 33(12):2981-2992. doi:10.1038/npp.2008.15

51. Sun H, Maze I, Dietz DM, Scobie KN, Kennedy PJ, DamezWerno D, Neve RL, Zachariou V et al (2012) Morphine epigenomically regulates behavior through alterations in histone H3 lysine 9 dimethylation in the nucleus accumbens. J Neurosci 32(48):17454-17464. doi:10.1523/JNEUROSCI.1357-12.2012

52. Wang L, Lv Z, Hu Z, Sheng J, Hui B, Sun J, Ma L (2010) Chronic cocaine-induced H3 acetylation and transcriptional activation of CaMKIlalpha in the nucleus accumbens is critical for motivation for drug reinforcement. Neuropsychopharmacology 35(4):913928. doi:10.1038/npp.2009.193

53. Malvaez M, Mhillaj E, Matheos DP, Palmery M, Wood MA (2011) CBP in the nucleus accumbens regulates cocaine-induced histone acetylation and is critical for cocaineassociated behaviors. J Neurosci 31(47):16941-16948. doi:10.1523/JNEUROSCI. 274711.2011

54. Malvaez M, McQuown SC, Rogge GA, Astarabadi M, Jacques V, Carreiro S, Rusche JR, Wood MA (2013) HDAC3-selective inhibitor enhances extinction of cocaine-seeking behavior in a persistent manner. Proc Natl Acad Sci U S A 110(7):2647-2652. doi: 10.1073/pnas.1213364110

55. Renthal W, Maze I, Krishnan V, Covington HE 3rd, Xiao G, Kumar A, Russo SJ, Graham A et al (2007) Histone deacetylase 5 epigenetically controls behavioral adaptations to chronic emotional stimuli. Neuron 56(3):517-529. doi:10.1016/j.neuron.2007. 09.032

56. Kennedy PJ, Feng J, Robison AJ, Maze I, Badimon A, Mouzon E, Chaudhury D, DamezWerno DM et al (2013) Class I HDAC inhibition blocks cocaine-induced plasticity by targeted changes in histone methylation. Nat Neurosci 16(4):434-440. doi:10.1038/ nn.3354

57. Renthal W, Kumar A, Xiao G, Wilkinson M, Covington HE 3rd, Maze I, Sikder D, Robison AJ et al (2009) Genome-wide analysis of chromatin regulation by cocaine reveals a role for sirtuins. Neuron 62(3):335-348. doi:10.1016/j.neuron.2009.03.026

58. Renthal W, Carle TL, Maze I, Covington HE 3rd, Truong HT, Alibhai I, Kumar A, Montgomery RL et al (2008) Delta FosB mediates epigenetic desensitization of the cfos gene after chronic amphetamine exposure. J Neurosci 28(29):7344-7349. doi:10. 1523/JNEUROSCI.1043-08.2008

59. Maze I, Covington HE 3rd, Dietz DM, LaPlant Q, Renthal W, Russo SJ, Mechanic M, Mouzon E et al (2010) Essential role of the histone methyltransferase G9a in cocaineinduced plasticity. Science 327(5962):213-216. doi:10.1126/science.1179438

60. Robison AJ, Vialou V, Mazei-Robison M, Feng J, Kourrich S, Collins M, Wee S, Koob G et al (2013) Behavioral and structural responses to chronic cocaine require a feedforward loop involving DeltaFosB and calcium/calmodulin-dependent protein kinase II in the nucleus accumbens shell. J Neurosci 33(10):4295-4307. doi: 10.1523/JNEUROSCI.5192-12.2013

61. Luscher C, Malenka RC (2011) Drug-evoked synaptic plasticity in addiction: from molecular changes to circuit remodeling. Neuron 69(4):650-663.

doi:10.1016/j.neuron.2011.01.017 
62. Chandrasekar V, Dreyer JL (2009) microRNAs miR-124, let-7d and miR-181a regulate cocaine-induced plasticity. Mol Cell Neurosci 42(4):350-362. doi:10.1016/j.mcn.2009.08.009

63. Hollander JA, Im HI, Amelio AL, Kocerha J, Bali P, Lu Q, Willoughby D, Wahlestedt C et al (2010) Striatal microRNA controls cocaine intake through CREB signalling. Nature 466(7303): 197-202. doi:10.1038/nature09202

64. Jonkman S, Kenny PJ (2013) Molecular, cellular, and structural mechanisms of cocaine addiction: a key role for microRNAs. Neuropsychopharmacology 38(1):198-211. doi:10.1038/npp. 2012.120

65. Schaefer A, Im HI, Veno MT, Fowler CD, Min A, Intrator A, Kjems J, Kenny PJ et al (2010) Argonaute 2 in dopamine 2 receptor-expressing neurons regulates cocaine addiction. J Exp Med 207(9):1843-1851. doi:10.1084/jem.20100451

66. Saba R, Storchel PH, Aksoy-Aksel A, Kepura F, Lippi G, Plant TD, Schratt GM (2012) Dopamine-regulated microRNA MiR-181a controls GluA2 surface expression in hippocampal neurons. Mol Cell Biol 32(3):619-632. doi:10.1128/MCB.05896-11

67. Vassoler FM, White SL, Schmidt HD, Sadri-Vakili G, Pierce RC (2013) Epigenetic inheritance of a cocaine-resistance phenotype. Nat Neurosci 16(1):42-47. doi:10.1038/nn.3280

68. Sasaki A, Constantinof A, Pan P, Kupferschmidt DA, McGowan PO, Erb S (2014) Cocaine exposure prior to pregnancy alters the psychomotor response to cocaine and transcriptional regulation of the dopamine D1 receptor in adult male offspring. Behav Brain Res 265:163-170. doi:10.1016/j.bbr.2014.02.017

69. Abel EL (1993) Rat offspring sired by males treated with alcohol. Alcohol 10(3):237242

70. Abel EL (1989) Paternal and maternal alcohol consumption: effects on offspring in two strains of rats. Alcohol Clin Exp Res 13(4):533-541

71. Finegersh A, Homanics GE (2014) Paternal alcohol exposure reduces alcohol drinking and increases behavioral sensitivity to alcohol selectively in male offspring. PLoS One 9(6):e99078. doi: 10.1371/journal.pone.0099078

72. Lu H, Lim B, Poo MM (2009) Cocaine exposure in utero alters synaptic plasticity in the medial prefrontal cortex of postnatal rats. J Neurosci 29(40):12664-12674. doi:10.1523/JNEUROSCI. 1984-09.2009

73. Buckingham-Howes S, Berger SS, Scaletti LA, Black MM (2013) Systematic review of prenatal cocaine exposure and adolescent development. Pediatrics 131(6):e19171936. doi:10.1542/peds. 2012-0945

74. Lambert BL, Bauer CR (2012) Developmental and behavioral consequences of prenatal cocaine exposure: a review. J Perinatol 32(11):819-828. doi:10.1038/jp.2012.90

75. Bellone $C$, Mameli M, Luscher C (2011) In utero exposure to cocaine delays postnatal synaptic maturation of glutamatergic transmission in the VTA. Nat Neurosci 14(11):1439-1446. doi: 10.1038/nn.2930

76. Kabir ZD, Katzman AC, Kosofsky BE (2013) Molecular mechanisms mediating a deficit in recall of fear extinction in adult mice exposed to cocaine in utero. PLoS One 8(12):e84165. doi:10. 1371/journal.pone.0084165

77. Foldi CJ, Eyles DW, Flatscher-Bader T, McGrath JJ, Burne TH (2011) New perspectives on rodent models of advanced paternal age: relevance to autism. Front Behav Neurosci 5:32. doi:10.3389/ fnbeh.2011.00032

78. Garcia-Palomares S, Pertusa JF, Minarro J, Garcia-Perez MA, Hermenegildo C, Rausell F, Cano A, Tarin JJ (2009) Long-term effects of delayed fatherhood in mice on postnatal 
development and behavioral traits of offspring. Biol Reprod 80(2):337-342. doi:10.1095/biolreprod.108.072066

79. Milekic MH, Xin Y, O'Donnell A, Kumar KK, Bradley-Moore M, Malaspina D, Moore H, Brunner D et al (2015) Age-related sperm DNA methylation changes are transmitted to offspring and associated with abnormal behavior and dysregulated gene expression. Mol Psychiatry 20(8):995-1001. doi:10.1038/mp.2014.84

80. Anway MD, Cupp AS, Uzumcu M, Skinner MK (2005) Epigenetic transgenerational actions of endocrine disruptors and male fertility. Science 308(5727):1466-1469. doi:10.1126/ science.1108190

81. Anway MD, Memon MA, Uzumcu M, Skinner MK (2006) Transgenerational effect of the endocrine disruptor vinclozolin on male spermatogenesis. J Androl 27(6):868-879. doi:10.2164/ jandrol.106.000349

82. Crews D, Gore AC, Hsu TS, Dangleben NL, Spinetta M, Schallert T, Anway MD, Skinner MK (2007) Transgenerational epigenetic imprints on mate preference. Proc Natl Acad Sci U S A 104(14): 5942-5946. doi:10.1073/pnas.0610410104

83. Crews D, Gillette R, Scarpino SV, Manikkam M, Savenkova MI, Skinner MK (2012) Epigenetic transgenerational inheritance of altered stress responses. Proc Natl Acad Sci U S A 109(23): 9143-9148. doi:10.1073/pnas.1118514109

84. Skinner MK, Anway MD, Savenkova MI, Gore AC, Crews D (2008) Transgenerational epigenetic programming of the brain transcriptome and anxiety behavior. PLoS One 3(11):e3745. doi: 10.1371/journal.pone.0003745

85. Skinner MK, Anway MD (2005) Seminiferous cord formation and germ-cell programming: epigenetic transgenerational actions of endocrine disruptors. Ann N Y Acad Sci 1061:18-32. doi:10. 1196/annals.1336.004

86. Skinner MK, Manikkam M, Haque MM, Zhang B, Savenkova MI (2012) Epigenetic transgenerational inheritance of somatic transcriptomes and epigenetic control regions. Genome Biol 13(10):R91. doi:10.1186/gb-2012-13-10-r91

87. Guerrero-Bosagna CM, Skinner MK (2009) Epigenetic transgenerational effects of endocrine disruptors on male reproduction. Semin Reprod Med 27(5):403-408. doi:10.1055/s-0029- 1237428

88. Guerrero-Bosagna C, Settles M, Lucker B, Skinner MK (2010) Epigenetic transgenerational actions of vinclozolin on promoter regions of the sperm epigenome. PLoS One 5(9):e13100. doi:10. 1371/journal.pone.0013100

89. Gillette R, Miller-Crews I, Nilsson EE, Skinner MK, Gore AC, Crews D (2014) Sexually dimorphic effects of ancestral exposure to vinclozolin on stress reactivity in rats. Endocrinology 155(10): 3853-3866. doi:10.1210/en.2014-1253

90. Walker DM, Gore AC (2011) Transgenerational neuroendocrine disruption of reproduction. Nat Rev Endocrinol 7(4):197-207. doi:10.1038/nrendo.2010.215

91. Anderson LM, Riffle L, Wilson R, Travlos GS, Lubomirski MS, Alvord WG (2006) Preconceptional fasting of fathers alters serum glucose in offspring of mice. Nutrition 22(3):327-331. doi:10. 1016/j.nut.2005.09.006

92. Skinner MK (2010) Metabolic disorders: fathers' nutritional legacy. Nature 467(7318):922-923. doi:10.1038/467922a

93. Wei Y, Yang CR, Wei YP, Zhao ZA, Hou Y, Schatten H, Sun QY (2014) Paternally induced transgenerational inheritance of susceptibility to diabetes in mammals. Proc Natl Acad Sci U S A 111(5): 1873-1878. doi:10.1073/pnas.1321195111 
94. Kaati G, Bygren LO, Edvinsson S (2002) Cardiovascular and diabetes mortality determined by nutrition during parents' and grandparents' slow growth period. Eur J Hum Genet 10(11): 682-688. doi:10.1038/sj.ejhg.5200859

95. Pembrey ME, Bygren LO, Kaati G, Edvinsson S, Northstone K, Sjostrom M, Golding J, Team AS (2006) Sex-specific, male-line transgenerational responses in humans. Eur J Hum Genet 14(2): 159-166. doi:10.1038/sj.ejhg.5201538

96. Carone BR, Fauquier L, Habib N, Shea JM, Hart CE, Li R, Bock C, Li C et al (2010) Paternally induced transgenerational environmental reprogramming of metabolic gene expression in mammals. Cell 143(7):1084-1096. doi:10.1016/j.cell.2010.12.008

97. Yamaguchi R, Nakagawa Y, Liu YJ, Fujisawa Y, Sai S, Nagata E, Sano S, Satake E et al (2010) Effects of maternal high-fat diet on serum lipid concentration and expression of peroxisomal proliferator-activated receptors in the early life of rat offspring. Horm Metab Res 42(11):821- 825. doi:10.1055/s-0030-1261954

98. Radford EJ, Ito M, Shi H, Corish JA, Yamazawa K, Isganaitis E, Seisenberger S, Hore TA et al (2014) In utero effects. In utero undernourishment perturbs the adult sperm methylome and intergenerational metabolism. Science 345(6198):1255903. doi:10. $1126 /$ science. 1255903

99. Hajkova $P$ (2011) Epigenetic reprogramming in the germline: towards the ground state of the epigenome. Philos Trans R Soc Lond B Biol Sci 366(1575):2266- 2273. doi:10.1098/rstb.2011.0042

100. Stringer JM, Barrand S, Western P (2013) Fine-tuning evolution: germ-line epigenetics and inheritance. Reproduction 146(1):R37- 48. doi:10.1530/REP-12-0526

101. Weaver JR, Susiarjo M, Bartolomei MS (2009) Imprinting and epigenetic changes in the early embryo. Mamm Genome 20(9- 10):532-543. doi:10.1007/s00335009-9225-2

102. Reik W, Dean W, Walter J (2001) Epigenetic reprogramming in mammalian development. Science 293(5532):1089-1093. doi:10. 1126/science.1063443

103. Seisenberger S, Andrews S, Krueger F, Arand J, Walter J, Santos F, Popp C, Thienpont $B$ et al (2012) The dynamics of genomewide DNA methylation reprogramming in mouse primordial germ cells. Mol Cell 48(6):849-862. doi:10.1016/j.molcel.2012.11.001

104. Hajkova P, Jeffries SJ, Lee C, Miller N, Jackson SP, Surani MA (2010) Genomewide reprogramming in the mouse germ line entails the base excision repair pathway. Science 329(5987):78-82. doi:10.1126/science.1187945

105. Hajkova P, Erhardt S, Lane N, Haaf T, El-Maarri O, Reik W, Walter J, Surani MA (2002) Epigenetic reprogramming in mouse primordial germ cells. Mech Dev 117(12):15- 23

106. Ginsburg S, Jablonka E (2009) Epigenetic learning in non-neural organisms. J Biosci 34(4):633-646

107. Gluckman PD, Hanson MA, Beedle AS (2007) Non-genomic transgenerational inheritance of disease risk. Bioessays 29(2): 145-154. doi:10.1002/bies.20522

108. Jablonka E, Lamb MJ (2005) Evolution in four dimensions: genetic, epigenetic, behavioral, and symbolic variation in the history of life. MIT Press, Cambridge 